\title{
Visual rehabilitation training in a patient with large central scotoma due to Leber's hereditary optic neuropathy
}

\author{
Agnieszka Kiszka', Dominika Nowakowska, Katarzyna Nowomiejska', Katarzyna Tońska', \\ Robert Rejdak ${ }^{1,3}$ \\ 'Department of General Ophthalmology, Medical University of Lublin, Poland \\ ${ }^{2}$ Institute of Genetics and Biotechnology, University of Warsaw, Warsaw, Poland \\ ${ }^{3}$ Department of Experimental Pharmacology, Medical Research Centre, Polish Academy of Sciences, Warsaw, Poland
}

\begin{abstract}
BACKGROUND: Leber's hereditary optic neuropathy (LHON) is a disease associated with pathogenetic mutations of mitochondrial DNA which affects predominantly young adult males and leads to loss of central vision, low visual acuity and unstable fixation. The purpose of this study was to allow the patient to establish the best possible fixation in the best area of retinal sensitivity in LHON patient with central scotoma.

METHODS: A 17 years old patient with confirmed mitochondrial LHON 11778G > A mutation was included in the study. The patient underwent 16 visual rehabilitation sessions - two for each of 8 weeks using the training module available in the equipment - MAIA microperimeter. Visual acuity and standrad microperimetry examination were performed before and 8 weeks period of training. To measure the fixation stability with MAIA microperimeter, P1, P2 and Bivariate Contour Ellipse Area (BCEA) parameters were used.

RESULTS: Visual acuity of the trained better eye was 0.08 at the baseline versus 0.063 after 8 weeks training. Fixation stability parameter was $\mathrm{P} 1-21 \%, \mathrm{P} 2-64 \%$ at the first session versus $\mathrm{P} 1-60 \%, \mathrm{P} 2-90 \%$ at the last session. BCEA values $29.2^{\circ 2}$ before and $14.2^{\circ 2}$ after training, respectively.

CONCLUSIONS: Visual training via microperimetry could potentially be a method that improves the fixation stability in patients with LHON.
\end{abstract}

KEY WORDS: Leber's hereditary optic neuropathy, eccentric viewing, eye-fixation training, microperimetry

Ophthalmol J 2018; Vol. 3, No. 1, 21-27

\section{INTRODUCTION}

Leber's hereditary optic neuropathy (LHON) is a disease associated with pathogenetic mutations of mitochondrial DNA (mtDNA), mostly at the nucleotide position (np) $11778 \mathrm{G}$ to $\mathrm{A}$, $3460 \mathrm{G}$ to $\mathrm{A}$ or $14484 \mathrm{~T}$ to $\mathrm{C}$. The disease begins with the central visual loss in one eye, and later progresses to the other eye. Patients usually exhibit very low visual acuity (below 0.1 ). Addi- tionally, central or centrocecal visual field defect typically occurs.

For detailed evaluation of central vision, there are still obstacles and limitations to overcome with classical perimetry. The limitations of conventional perimetry, mainly in patients with low vision, include lack of precision and reproducibility, due to movements of the eye and reduced sensitivity with small scotomas. The inability to determine 
the characteristics of fixation, and to identify the retinal preferential locus (extrafovealfixation point) and less exact topographical correlation in spacial localization of the stimulus, makes microperimetry a superior study in this sense [1,2]. Microperimetry examination allows for retinal sensitivity patterns mapping and fixation analysis. Microperimetry can also be used as a tool for eccentric viewing eye-fixation training. Training aims to create new and more functional eye-fixation point with an increase in its stability. It has been described that fixation can be trained and it is possible to establish new fixation points in patients with loss of central vision. The advantages of microperimetry include good reproducibility in comparative studies (to value the same points of the retina evaluated during the microperimetry base exactly), the ability to be operated in non-mydriaticconditions, and the possibility of personalizing most of the test parameters (the fundus, the type and color of the fixation target, and the stimulus duration), allowing one to adapt the exam to each specific patient and their pathology [3]. Microperimetry has several applications that are helpful in guiding rehabilitation efforts and teaching patients to locate and maximie use of their areas of best vision. This technique supplements and improves the psychophysical evaluation of optic neuropathy. In the absence of retinal macular disease, microperimetry allows accurate study of the effect of secondary retinal sensitivity due to loss of ganglion cells and axons at the level of the papillomacular bundle [4]. Microperimetry systems with biofeedback training have been used for visual rehabilitation and for improving fixation stability in patients with eccentric vision [5].

The purpose of this study was to allow the patient with LHON to estabilish the best possible fixation in the best area of retinal sensitivity by using microperimetry.

\section{CASE DESCRIPTION}

Seventeen years-old patient was admitted to the Department of Opthtalmology in November 2017 because of progressing vision deterioration in the right eye since June 2017. In clinical examination visual acuity of the right eye was counting fingers to 0.5 meter, in the left eye -1.0 with Snellen chart without correction. Anterior segment examination in the slit-lamp was within normal limits, the reaction of pupils to light was correct. The fundus examination did not reveal any abnormalities. The static perimetry showed characteristic central scotoma in both eyes, bigger in the right eye. Semi-automated kinetic perimetry using a III4e and $\mathrm{V} 4 \mathrm{e}$ target confirmed an absolute central scotoma of area 63 square degrees tested by V4e target and 201.5 square degrees using III4e target in the right eye. In the left eye it was 5.7 degrees and 7.3 degrees, respectively (Fig. 1). The therapy with Ibe-

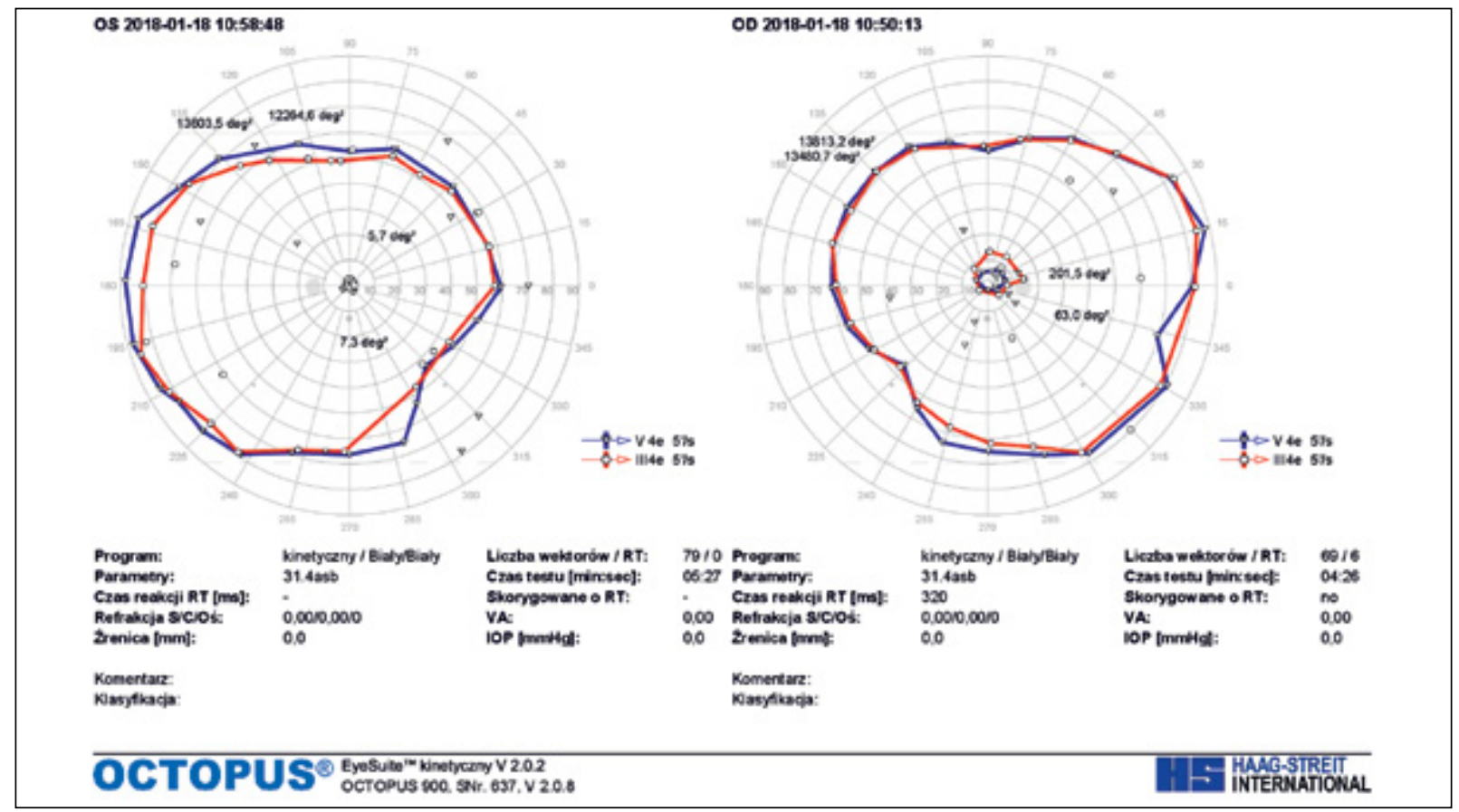

FIGURE 1. Semiautomated kinetic perimetry results illustrating central field loss 


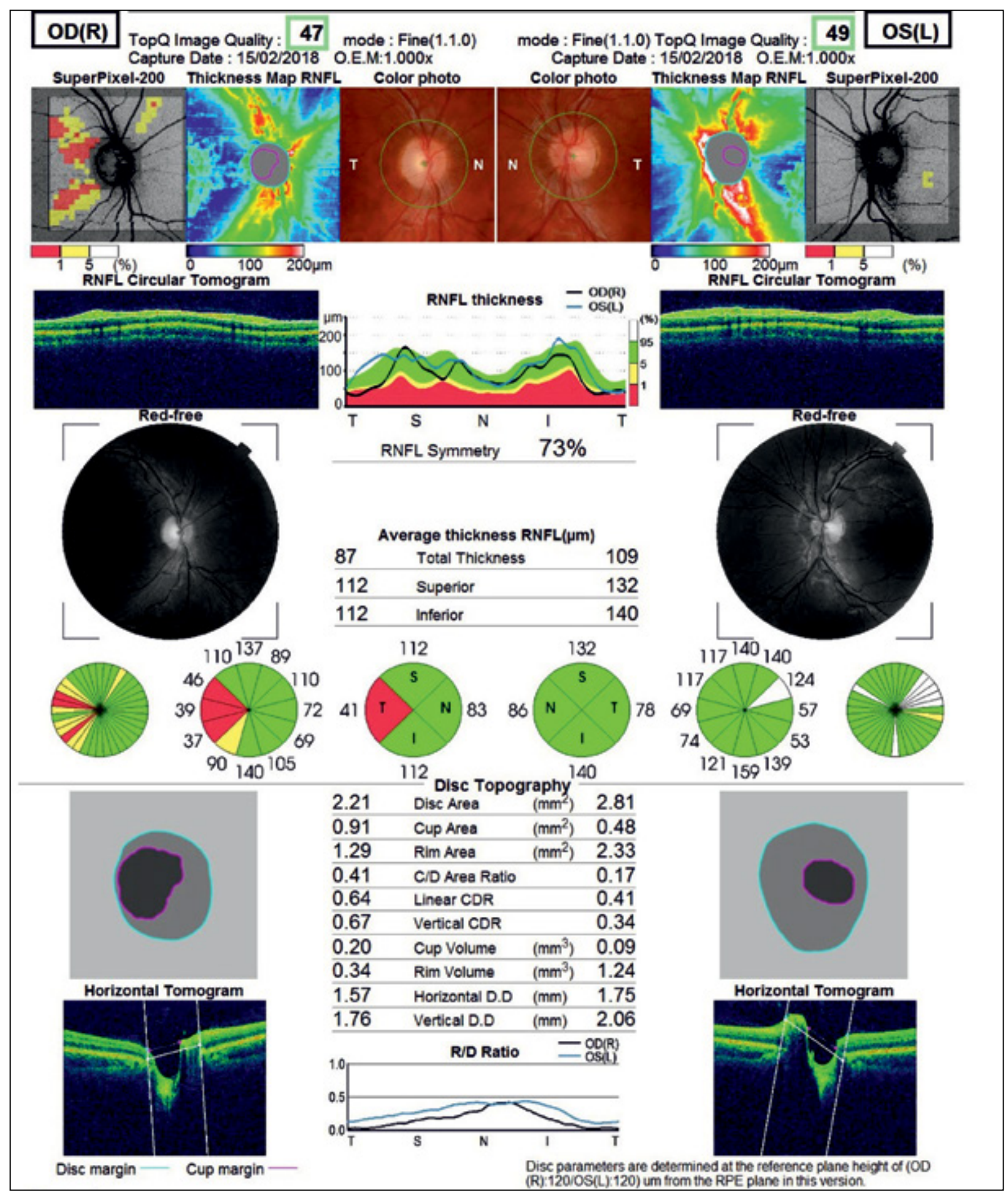

FIGURE 2. Optical coherence tomography (OCT) — decreased peripapillary nerve fibre layer (RNFL) in the right eye and increased thickness in the left eye

denone 3 x 300 p.o. was introduced. Additionally, genetic testing was done in the Institute of Genetics and Biotechnology of University of Warsaw, which confirmed mtDNA m11778G > A mutation. After 3 months, in February, the visual acuity was counting fingers to 0.5 meter in the right eye and 0.1 in the left eye with Snellen chart without correction. Optical coherence tomography (OCT) showed decreased peripapillary nerve fibre layer (RNFL) in the right eye, but RNFL thickness in the left eye was increased (Fig. 2). An acute phase of the disease has been confirmed in the left eye. Additionally, 


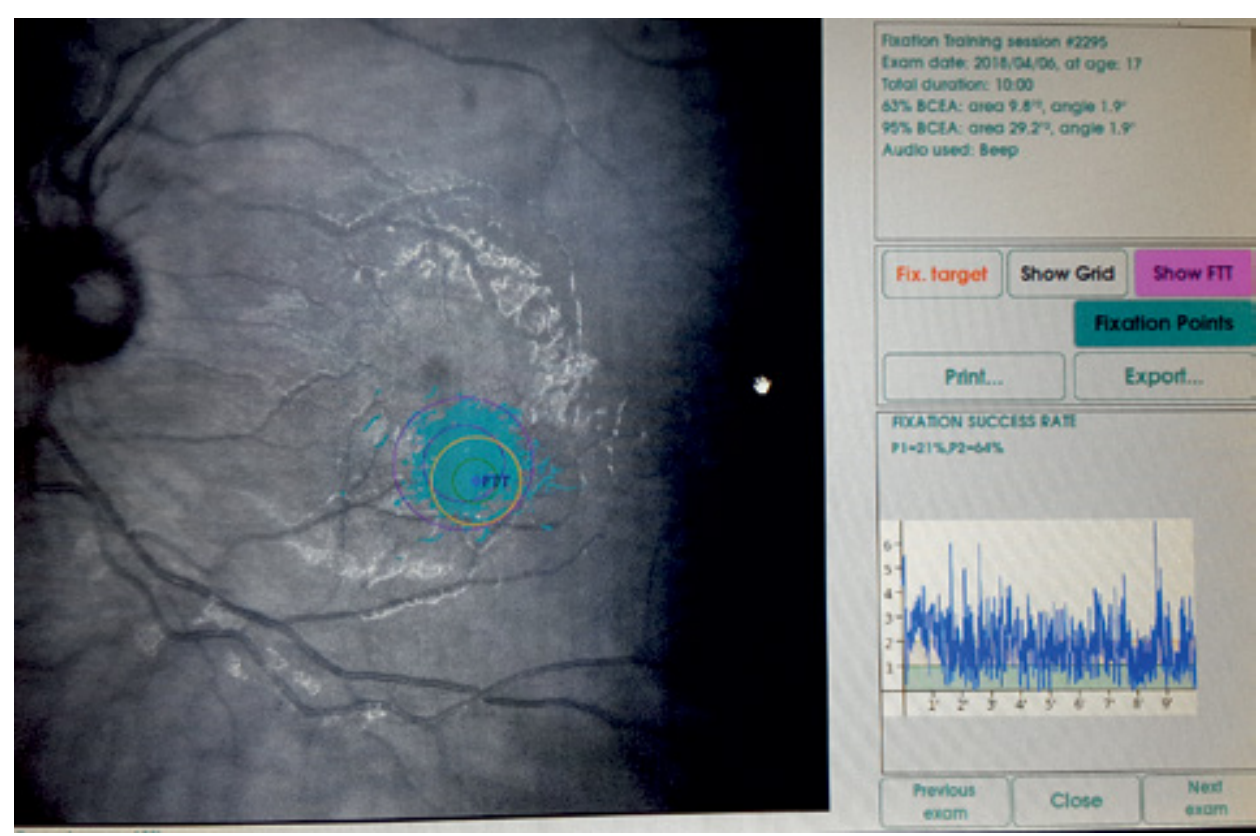

FIGURE 3. The result of the first visual rehabilitation training of the left eye in the patient with LHON: unstable fixation

visual evoked potentials (VEP) were performed and showed reduced P100 wave amplitude. The visual rehabilitation was started in May.

MAIA (Macular Integrity Assessment) microperimeter (CentreVue, Padova, Italy) was used to determine the retinal fixation and sensitivity in this patient 8 months after onset of LHON. The patient underwent visual rehabilitation sessions using the training module available in the equipment. Visual rehabilitation program included two training sessions of 10 minutes with 20 minutes time intervals, in the better eye, once a week for 8 weeks as it was described in similar studies [5]. As the result of standard microperimetry examination the new desired fixation point - Preferred Retinal Target (PRT), was selected. The MAIA has a high-resolution fundus camera of $1024 \times 1024$ pixels and a high-frequency eye tracking system. This provides light stimuli in an accurate and repeatable way on precise areas of the retina, evaluating retinal sensitivity in specific points in a reliable and reproducible way. It also offers a map of the fixation area used by the patient.

Visual acuity with the use of Snellen charts was assessed before and after training to determine the training effectiveness. Additionally, standard microperimetry examination was performed before and after 8 weeks period. Changes in the retinal sensitivity were documented by "follow-up" option of MAIA. For fixation stability measurement pa- rameters as P1 and 95\% Bivariate Contour Ellipse Area (BCEA) were used. P1 expresses in percentage the number of fixation points that are within the area of a circle with 1-degree diameter, 95\% BCEA value establishes the ellipse area, expressed in square degrees, comprising $95 \%$ of the fixations points used by the patient during the test. Therefore, higher P1 values and lower 95\% BCEA values indicate a better fixation capacity.

Best Corrected Visual Acuity (BCVA) of the trained eye was 0.08 versus 0.0638 weeks after training. Fixation stability improved with P1-21\%, P2-64\% (Fig. 3) versus P1-60\%, P2-90\% (Fig. 4) and $95 \%$ BCEA values were $29.2^{\circ 2}$ (Fig. 3) before and $14.2^{\circ 2}$ (Fig. 4) after training, respectively.

\section{DISCUSSION}

Fixation is required to detect the details of an object and it occurs physiologically on the fovea. It has been described in the literature that improvement in fixation implies an improvement in the visual capacity [6]. There are studies describing visual acuity and fixation stability improvement by visual rehabilitation, using microperimeter MAIA, in patients with successful closure of macular hole [7], AMD [8] and another studies carried out on the device MP-1 in patients with myopic macular degeneration and other macular diseases [9-11]. Additionally, it has been proven that microperimetry is a useful tool for 


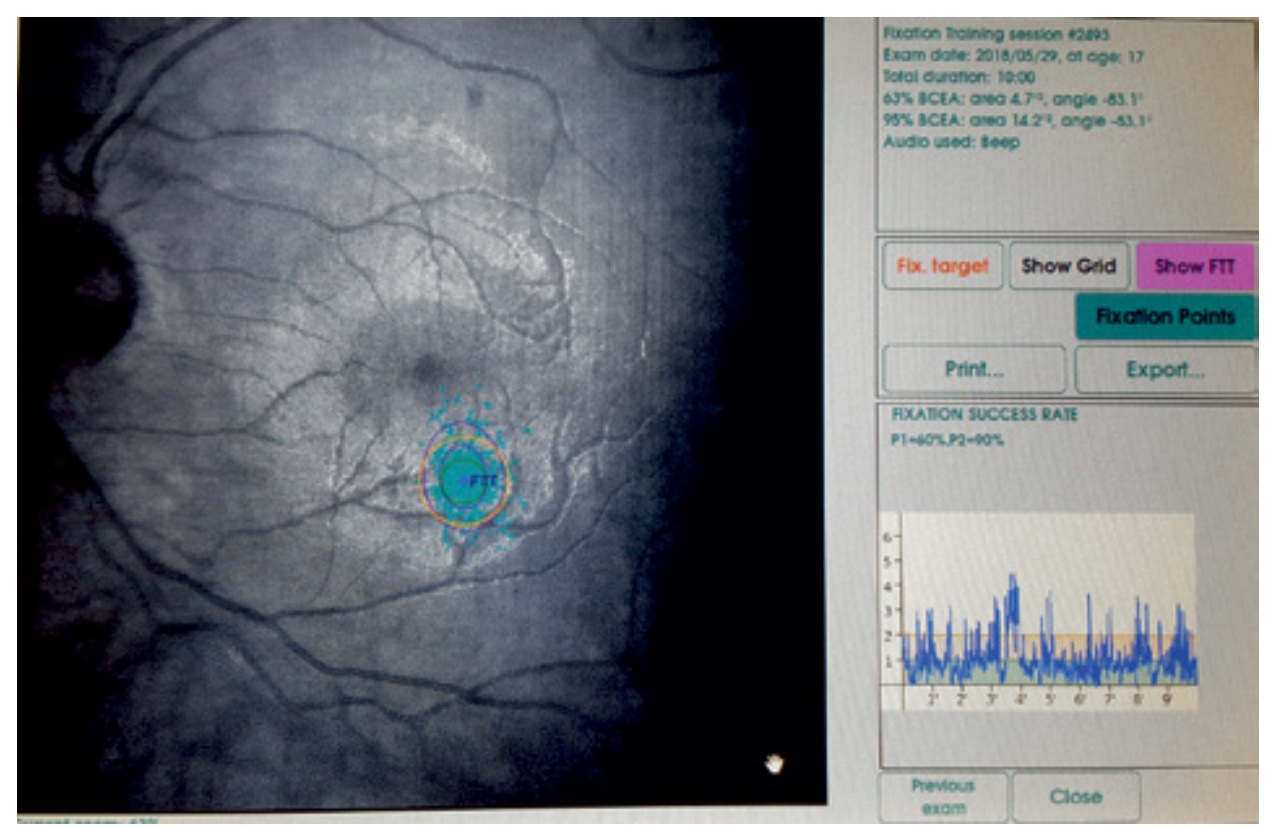

FIGURE 4. The result of visual rehabilitation training of the left eye after 16 visual rehabilitation sessions -2 for each of 8 weeks in the patient with LHON: more stable fixation

the follow-up of patients with diabetic retinopathy [12-15], central serous chorioretinopathy $[16,17]$, uveitic macular edema [18], macular dystrophies such as Stargardt disease [19], and AMD, in the latter evidencing a decrease in retinal sensitivity and fixation quality when the disease progresses [20]. There are also studies presenting microperimetry (MP-1) diagnostic utility in the evaluation of the disorders of the optic nerve such as epidemic optic neuropathy (EON) [21-26], dominant optic atrophies (DOA) [27, 28], LHON [26-30], thyroid associated orbitopathy to the (TAO) $[27,28,31]$ and multiple sclerosis $[27,28,32]$.

In the present study visual rehabilitation using MAIA microperimeter showed significant improvement in the fixation pattern, but improvement of the visual acuity was minimal.

To date, there are no publications in existence demonstrating the effectiveness of MAIA in visual rehabilitation of patients with LHON. However, central scotoma in LHON lead to difficulties with reading, thus visual rehabilitation seems to be very important for these patients to continue their education and their ability to work [33]. The visual improvement in LHON patients has also been observed during follow-up and it is possibly the adaptive phenomenon of eccentric fixation [34]. Eccentric viewing (EV), a representative method of visual function training, consists of using any non-foveal point on the retina for viewing [35].
The fovea is located at the center of the macula and is the core area used for fixation in the healthy retina; however, when the central retina is damaged, the eye must utilize a new retinal area for viewing. A previous study reported that during EV training [36], a preferred retinal locus (PRL) can develop to replace the fovea and has been suggested to be the most important factor in EV training [37-39]. Eccentric PRLs have been known to exist for many years and develops in approximately $84 \%$ of eyes affected by central scotoma [40]. However, the factors determining the development of a PRL at a precise location relative to the scotoma and their characteristics are still not well understood. Previous studies have reported that PRLs were more frequently located relative to a specific location of the scotoma, although, the reports regarding the precise location are conflicting [40-42]. Visual training via microperimetry is controlled by the rehabilitator; guided by a sound system, which encourages to find and maintain the fixation on an established point (PRT). This requires the patient to have good comprehension skills and understanding of the tests and the process; furthermore, requires time availability and motivation, important factors in view of patients who are candidates for this type of training. Microperimetry studies carried out in 2005, as part of visual rehabilitation at the Rome University Ophthalmology Department, showed that fixation within the central $2^{\circ}$ of the visual field determines the best visual 
acuity, and reduces saccadic movement amplitudes when following a text [43]. The duration of training has not been established to obtain optimal results; neither when a new training, if required, should be done. The limitation of our study is that it is only one case report. We need more research to determine what the outcome is, and a favorable outcome in the patient with this kind of rehabilitation.

\section{CONCLUSION}

The results presented in this study demonstrate that visual training via microperimetry in patients with LHON could potentially be a method that improves fixation stability. It is very important especially for these patients who suffer from a disabling condition without effective of methods treatment to date.

\section{REFERENCES}

1. Sunness JS, Schuchard RA, Shen N, et al. Landmark-driven fundus perimetry using the scanning laser ophthalmoscope. Invest Ophthalmol Vis Sci. 1995; 36(9): 1863-1874, indexed in Pubmed: 7635660.

2. Hwang JC, Tari SR, Seiple W, et al. Reproducibility of Eye Movement Compensated Fundus Perimetry. Investigative Ophthalmology \& Visual Science. 2005; 46: 1561.

3. Springer C, Bültmann $\mathrm{S}$, Völcker HE, et al. Fundus perimetry with the Micro Perimeter 1 in normal individuals: comparison with conventional threshold perimetry. Ophthalmology. 2005; 112(5): 848-854, doi: 10.1016/j.ophtha.2004.11.051, indexed in Pubmed: 15878065.

4. Mendoza-Santiesteban CE, Lopez-Felipe D, Fernández-Cherkasova $\mathrm{L}$, et al. Microperimetry in the study of neuro-ophthalmic diseases. Semin Ophthalmol. 2010; 25(4): 136-143, doi: 10.3109/08820538.2010.500201, indexed in Pubmed: 20695734.

5. Morales MU, Saker S, Amoaku WM. Bilateral eccentric vision training on pseudovitelliform dystrophy with microperimetry biofeedback. BMJ Case Rep. 2015; 2015, doi: 10.1136/bcr-2014-207969, indexed in Pubmed: 25576513.

6. Giacomelli G, Virgili G, Giansanti F, et al. Clinical and microperimetric predictors of reading speed in low vision patients: a structural equation modeling approach. Invest Ophthalmol Vis Sci. 2013; 54(6): 44034408, doi: 10.1167/iovs.12-10734, indexed in Pubmed: 23722392.

7. Ueda-Consolvo $T$, Otsuka $M$, Hayashi $Y$, et al. Microperimetric Biofeedback Training Improved Visual Acuity after Successful Macular Hole Surgery. J Ophthalmol. 2015; 2015: 572942, doi: 10.1155/2015/572942, indexed in Pubmed: 26783452.

8. Ramírez Estudillo JA, León Higuera MI, Rojas Juárez S, et al. Visual rehabilitation via microperimetry in patients with geographic atrophy: a pilot study. Int J Retina Vitreous. 2017; 3: 21, doi: 10.1186/s40942017-0071-1, indexed in Pubmed: 28536656.

9. Tarita-Nistor L, González EG, Markowitz SN, et al. Plasticity of fixation in patients with central vision loss. Vis Neurosci. 2009; 26(5-6): 487-494, doi: 10.1017/S0952523809990265, indexed in Pubmed: 20003597.

10. Vingolo EM, Salvatore $S$, Cavarretta S. Low-vision rehabilitation by means of MP-1 biofeedback examination in patients with different macular diseases: a pilot study. Appl Psychophysiol Biofeedback. 2009; 34(2): 127-133, doi: 10.1007/s10484-009-9083-4, indexed in Pubmed: 19396541.

11. Pacella E, Pacella F, Mazzeo F, et al. Effectiveness of vision rehabilitation treatment through MP-1 microperimeter in patients with visual loss due to macular disease. Clin Ter. 2012; 163(6): e423-e428, indexed in Pubmed: 23306757.
12. Yohannan J, Bittencourt M, Sepah YJ, et al. Association of retinal sensitivity to integrity of photoreceptor inner/outer segment junction in patients with diabetic macular edema. Ophthalmology. 2013; 120(6): 1254-1261, doi: 10.1016/j.ophtha.2012.12.003, indexed in Pubmed: 23499060.

13. Hatef $E$, Hanout $M$, Moradi $A$, et al. Longitudinal comparison of visual acuity as measured by the ETDRS chart and by the potential acuity meter in eyes with macular edema, and its relationship with retinal thickness and sensitivity. Eye (Lond). 2014; 28(10): 1239-1245, doi: 10.1038/eye.2014.182, indexed in Pubmed: 25104744.

14. Hatef $E$, Colantuoni E, Wang J, et al. The relationship between macular sensitivity and retinal thickness in eyes with diabetic macular edema. Am J Ophthalmol. 2011; 152(3): 400-405.e2, doi: 10.1016/j. ajo.2011.02.024, indexed in Pubmed: 21696702.

15. Okada K, Yamamoto $S$, Mizunoya $S$, et al. Correlation of retinal sensitivity measured with fundus-related microperimetry to visual acuity and retinal thickness in eyes with diabetic macular edema. Eye (Lond). 2006; 20(7): 805-809, doi: 10.1038/sj.eye.6702014, indexed in Pubmed: 16021181.

16. Ozdemir H, Karacorlu SA, Senturk F, et al. Assessment of macular function by microperimetry in unilateral resolved central serous chorioretinopathy. Eye (Lond). 2008; 22(2): 204-208, doi: 10.1038/ sj.eye.6702563, indexed in Pubmed: 16936642.

17. Roisman L, Ribeiro JC, Fechine FV, et al. Does microperimetry have a prognostic value in central serous chorioretinopathy? Retina. 2014; 34(4): 713-718, doi: 10.1097//AE.0b013e3182a323fe, indexed in Pubmed: 23975001.

18. Sepah YJ, Hatef E, Colantuoni E, et al. Macular sensitivity and fixation patterns in normal eyes and eyes with uveitis with and without macular edema. J Ophthalmic Inflamm Infect. 2012; 2(2): 65-73, doi: 10.1007/ s12348-011-0052-8, indexed in Pubmed: 22167465.

19. Verdina T, Giacomelli G, Sodi A, et al. Biofeedback rehabilitation of eccentric fixation in patients with Stargardt disease. Eur J Ophthalmol. 2013; 23(5): 723-731, doi: 10.5301/ejo.5000291, indexed in Pubmed: 23640508.

20. Meleth $A D$, Mettu $P, A g r o ́ n ~ E$, et al. Changes in retinal sensitivity in geographic atrophy progression as measured by microperimetry. Invest Ophthalmol Vis Sci. 2011; 52(2): 1119-1126, doi: 10.1167/ iovs.10-6075, indexed in Pubmed: 20926818.

21. National Operative Group. Epidemic Neuropathy in Cuba. Havana: Ministry of Public Health, 1993; 27: 7-30.

22. Santiesteban R, Márquez M. Neuro-ophthalmological and neurophysiological characteristics of the epidemic neuropathy. Epidemic Neuropathy in Cuba 1992-1994. Havana: Editorial Medical Sciences. ; 1995: 35-45.

23. Hirano M, Cleary JM, Stewart AM, et al. 'Outbreak' of optic and peripheral neuropathy in Cuba? JAMA. 1993; 270(4): 511-518, doi: 10.1001/ jama.1993.03510040115049, indexed in Pubmed: 8391588.

24. Torroni TO, Brown MD, Lott MT, et al. Cuba neuropathy field investigation. African, Native American, and European mitochondrial DNA in Cubans from Pinegrove of the River province and implications for the recent epidemic neuropathy in Cuba. Hum Mutat. 1995; 5: 310-317.

25. Hedges TR, Hirano M, Tucker K, et al. Epidemic optic and peripheral neuropathy in Cuba: a unique geopolitical public health problem. Surv Ophthalmol. 1997; 41(4): 341-353, doi: 10.1016/s00396257(96)00008-2, indexed in Pubmed: 9104771.

26. Barnouin J, Verdura Barrios T, Chassagne M, et al. Nutritional and food protection against epidemic emerging neuropathy. Epidemiological findings in the unique disease-free urban area of Cuba. Int J Vitam Nutr Res. 2001; 71(5): 274-285, doi: 10.1024/0300-9831.71.5.274, indexed in Pubmed: 11725692.

27. American Academy of Ophthalmology. Neuro Ophthalmology. Section 5. The sensory visual system. Basic and Clinical Science course 03-2004.

28. American Academy of Ophthalmology. Optic Nerve Disorders. Ophthalmology monographs 10 . Basic and Clinical Science course 03-2004:139-158.

29. Yu-Wai-Man P, Griffiths PG, Brown DT, et al. The epidemiology of Leber hereditary optic neuropathy in the North East of England. Am J Hum Genet. 2003; 72(2): 333-339, doi: 10.1086/346066, indexed in Pubmed: 12518276. 
30. Santiesteban R, et al. Rodríguez M Mendoza C M Clinical manifestations and molecular identification of patient with hereditary optic neuropatía of Leber in center of national reference for the neuroftalmología in Cuba. Magazine of Neurol. 1999; 29(5): 408-415.

31. Pérez Moreira JV. Pathology would orbit, exploration diagnosis and surgery. Tomoll España. 2002; 41: 949-988.

32. Poser CHM. An Atlas of Multiple Sclerosis. Boston: Department of Neurology, Harvard Medical School. 1998; 38: 16-19.

33. Leo-Kottler B, Christ-Adler M. [Leber optic neuropathy in women and children]. Ophthalmologe. 1999; 96(11): 698-701, doi: 10.1007/ s003470050479, indexed in Pubmed: 10631830.

34. Altpeter EK, Blanke BR, Leo-Kottler B, et al. Evaluation of fixation pattern and reading ability in patients with Leber hereditary optic neuropathy. J Neuroophthalmol. 2013; 33(4): 344-348, doi: 10.1097/ WNO.0b013e31829d1f5b, indexed in Pubmed: 24256876.

35. VON NOORDEN GK, MACKENSEN G. Phenomenology of eccentric fixation. Am J Ophthalmol. 1962; 53: 642-660, doi: 10.1016/00029394(62)91987-6, indexed in Pubmed: 13926696.

36. Holocomb JG, Goodrich GL. Eccentric viewing training. J Am Optom Assoc. 1976; 47(11): 1438-1443, indexed in Pubmed: 1025166.

37. Timberlake GT, Mainster MA, Peli E, et al. Reading with a macular scotoma. I. Retinal location of scotoma and fixation area. Invest Ophthalmol Vis Sci. 1986; 27(7): 1137-1147, indexed in Pubmed: 3721792.
38. Timberlake GT, Peli E, Essock EA, et al. Reading with a macular scotoma. II. Retinal locus for scanning text. Invest Ophthalmol Vis Sci. 1987; 28(8): 1268-1274, indexed in Pubmed: 3610545.

39. Whittaker SG, Budd J, Cummings RW. Eccentric fixation with macular scotoma. Invest Ophthalmol Vis Sci. 1988; 29(2): 268-278, indexed in Pubmed: 3338884.

40. Fletcher DC, Schuchard RA. Preferred retinal loci relationship to macular scotomas in a low-vision population. Ophthalmology. 1997; 104(4): 632-638, doi: 10.1016/s0161-6420(97)30260-7, indexed in Pubmed: 9111255.

41. Sunness JS, Applegate CA, Haselwood D, et al. Fixation patterns and reading rates in eyes with central scotomas from advanced atrophic age-related macular degeneration and Stargardt disease. Ophthalmology. 1996; 103(9): 1458-1466, doi: 10.1016/s0161-6420(96)30483-1, indexed in Pubmed: 8841306.

42. Crossland MD, Culham LE, Kabanarou SA, et al. Fixation stability and reading speed in patients with newly developed macular disease. Ophthalmic Physiol Opt. 2004; 24(4): 327-333, doi: 10.1111/j.1475-1313.2004.00213.x, indexed in Pubmed: 15228511.

43. Limol P, Vingolo EM, et al. D'Amato LM, Microperimetry and Fixation in the Low Vision Patient. Investigative Ophthalmology \& Visual Science. 2005; 46: 4330. 